\title{
Improved Lipid Profile Associated with Daily Consumption of Tri-Sura-Phon in Healthy Overweight Volunteers: An Open-Label, Randomized Controlled Trial
}

\author{
Sirigoon Kuamsub, ${ }^{1}$ Pariyaphat Singthong, ${ }^{2}$ Wipawee Chanthasri, ${ }^{1}$ \\ Nicharee Chobngam, ${ }^{1}$ Warissara Sangkaew, ${ }^{3}$ Sasithorn Hemdecho, ${ }^{1}$ \\ Thammarat Kaewmanee, ${ }^{4}$ and Sasitorn Chusri ${ }^{1}$ \\ ${ }^{1}$ Natural Product Research Center of Excellence and Faculty of Traditional Thai Medicine, Prince of Songkla University, \\ Hat Yai, Songkhla 90110, Thailand \\ ${ }^{2}$ Faculty of Thai Traditional and Alternative Medicine, Ubonratchathani Rajabhat University, Meung, \\ Ubonratchathani 34000, Thailand \\ ${ }^{3}$ Sirindhorn College of Public Health Trang, Kantang, Trang 92110, Thailand \\ ${ }^{4}$ Department of Food Science and Nutrition, Faculty of Science and Technology, Prince of Songkla University, \\ Pattani 94000, Thailand \\ Correspondence should be addressed to Sasitorn Chusri; sasitorn.chu@psu.ac.th
}

Received 19 January 2017; Revised 5 March 2017; Accepted 23 March 2017; Published 6 April 2017

Academic Editor: Michał Tomczyk

Copyright (C) 2017 Sirigoon Kuamsub et al. This is an open access article distributed under the Creative Commons Attribution License, which permits unrestricted use, distribution, and reproduction in any medium, provided the original work is properly cited.

Tri-Sura-Phon (TSP), a traditional Thai polyherbal formula renowned for its rejuvenating properties, is commonly used as a blood tonic. It comprises Cinnamomum bejolghota, Cinnamomum parthenoxylon, and Aquilaria crassna. The aim of this study is to evaluate the beneficial properties of TSP tea consumption on blood glucose regulation and serum lipid profiles of healthy overweight volunteers. This open-label, randomized controlled trial was conducted in 70 healthy overweight adults. Two groups of 35 subjects took a TSP infusion or a placebo (cornstarch) twice daily for 8 weeks. The blood glucose regulation, serum lipid profiles, BMI, and liver function tests of the subjects were determined at the baseline, 4th week, and endpoint (8th week). Significant decreases in the average fasting levels of total cholesterol $(p=0.013)$, triglyceride $(p=0.001)$, and low-density lipoprotein $(\mathrm{LDL}, p=0.017)$ were observed in the TSP group at the 8th week compared to those at the baseline. The average HDL level in the TSP group at the beginning of the study was $65.2 \mathrm{mg} / \mathrm{dL}$, and it increased significantly ( $p=0.005)$ to $72.4 \mathrm{mg} / \mathrm{dL}$ after 8 weeks of TSP intake. This study showed that the intake of TSP tea as an antioxidant-rich beverage might be safe and improve lipid profiles in overweight adults.

\section{Introduction}

Obesity has become a major global health concern because it is directly related to the incidence of type 2 diabetes [1], hypertension, hypercholesterolemia [2], acceleration of aging process [3], and arteriosclerosis. In addition, obesity is associated with significant increases in oxidative stress owing to the well-established relationship between oxidative stress and metabolic syndrome [4]. In vivo studies have clearly demonstrated that treating obese animal models with antioxidant agents attenuates the development of hyperlipidemia and diabetes $[5,6]$. In recent years, there has been a growing interest in natural bioactive compounds (especially plantderived antioxidants) that may protect humans from the aforementioned diseases. Some traditional medicinal plants that possess antioxidant activity and contain high amounts of phenolics are green tea (Camellia sinensis) [7], Salvia officinalis [8], Melissa officinalis [9], and Capparis spinosa [10]. 


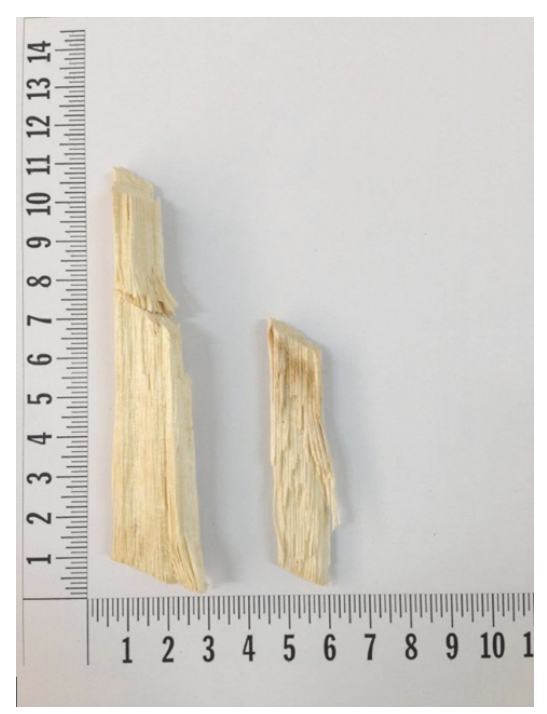

(a)

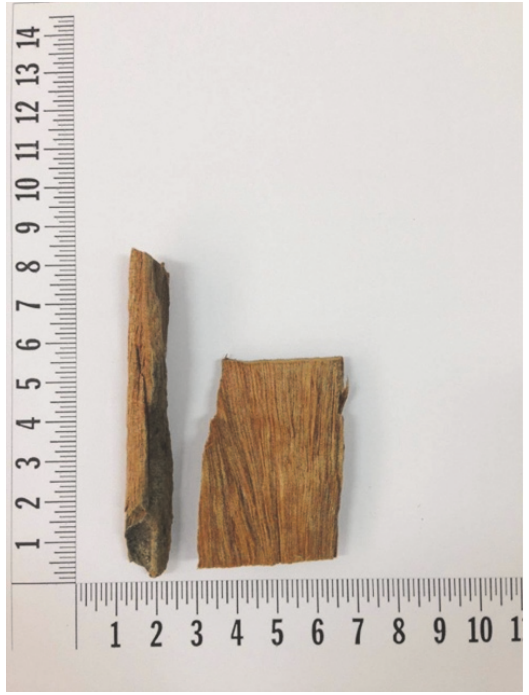

(b)

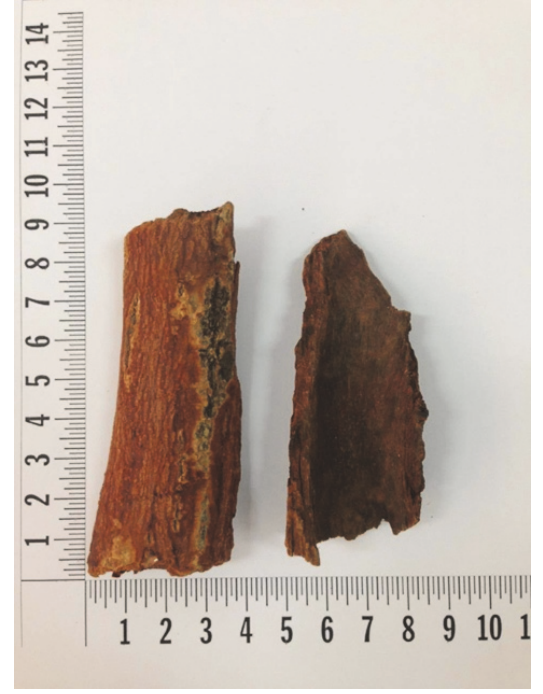

(c)

Figure 1: A polyherbal formulation, Tri-Sura-Phon, contains equal parts of Aquilaria crassna (a), Cinnamomum parthenoxylon (b), and Cinnamomum bejolghota (c).

These plants have been clinically proven to reduce the development of hyperlipidaemia and type 2 diabetes. Although intensive studies have been performed on these medicinal plants, very few studies have reported the potential benefits of antioxidant-rich herbal formulations described in traditional medicine. Studies have been extensively performed on Triphala, a polyherbal formula made from the fruits of Terminalia chebula, Terminalia bellirica, and Phyllanthus emblica. It has been widely described as a rejuvenator in Ayurvedic medicine. Triphala has notable health benefits as an effective antioxidant, chemopreventive, radioprotective, antidiabetic, and hypolipidemic agent both in vitro and in vivo $[11,12]$. It has also been clinically proven to be a promising antiplaque and antigingivitis agent [13].

According to the Thai Pharmaceutical Textbook, TriSura-Phon (TSP) is a simple formulation that comprises a mixture of powdered dried wood from Aquilaria crassna and Cinnamomum parthenoxylon, as well as the bark of Cinnamomum bejolghota. In Thai, Tri-Sura- Phon means three (Tri) medicinal plants that have potent (Sura-) health benefits (Phon) [14]. An earlier study conducted in our laboratory revealed that, among the 18 tested rejuvenative recipes used in traditional Thai medicine, TSP exhibits remarkable activity as DPPH (2,2-diphenyl-1-picrylhydrazyl) and ABTS $\left(2,2^{\prime}\right.$ azino-bis(3-ethylbenzthiazoline-6-sulphonic acid)) free radical scavengers and produces no cytotoxic effects on Vero cells [15]. Moreover, its herbal components have been credited with diverse beneficial properties such as antioxidant, anti-ischemic, antimicrobial, anticancer, hypoglycaemic, and hypolipidemic activities [16-18]. Besides this broad spectrum of biological activities, no toxic effects were observed at doses as high as 2000, 300, and $2500 \mathrm{mg} / \mathrm{kg}$ of A. crassna [18], C. parthenoxylon [16], and C. bejolghota [17], respectively, in in vivo studies.

Although Tri-Sura-Phon is traditionally used as a rejuvenating agent and blood tonic, to our knowledge, no clinical studies have been conducted to determine the beneficial effects of TSP consumption. This single centre, open-label, randomized controlled study was designed to evaluate the possible beneficial health effects of TSP tea consumption on fasting blood glucose (FBG) levels, insulin levels, lipid profiles, and liver functions in humans, and to compare these effects with those of a placebo. A pilot trial with healthy overweight volunteers had demonstrated that TSP tea consumption significantly improved blood lipid profiles without adverse effects. This information paves the way for future studies designed to test the hypolipidemic potential of TSP in patients with borderline hyperlipidemia.

\section{Material and Methods}

\subsection{Medicinal Plants}

2.1.1. Plant Materials. C. bejolghota (bark), A. crassna (wood), and C. parthenoxylon (wood) were obtained from the licensed traditional medical drug store, Triburi Orsot, in Songkla, Thailand (Figure 1). Voucher specimens of crude drugs (C. bejolghota; THP-R0051, A. crassna; THP-R0052, and C. parthenoxylon; THP-R0053) were deposited in the herbarium within the Faculty of Traditional Thai Medicine, Prince of Songkla University. The plant parts were cleaned, dried at $60^{\circ} \mathrm{C}$ for $72 \mathrm{~h}$ in an air blowing thermostatic oven, and stored in air tight containers at $4^{\circ} \mathrm{C}$ until further use. The plant materials were independently milled into powder, sieved, weighed $(1: 1: 1)$ in equal proportions, and then mixed to obtain Tri-Sura-Phon (TSP) as per the procedure described in the Thai Pharmaceutical Textbook [14].

2.1.2. Standardization of Medicinal Plants. The tested medicinal plants and TSP were standardized using their total phenolic and flavonoid contents, which were measured by 
the Folin-Ciocalteu assay and aluminium chloride reaction, respectively [19]. Tri-Sura-Phon $(500 \mathrm{~g})$ was submitted for hydrodistillation using a Clevenger-type apparatus at $100^{\circ} \mathrm{C}$ for $5 \mathrm{~h}$. Gas chromatography (GC) analysis was carried out using an Agilent 7890A GC System equipped with a flame ionization detector (FID). A TRACE ${ }^{\mathrm{TM}}$ TR-1MS fused-silica capillary column $(30 \mathrm{~m} \times 0.32 \mathrm{~mm}$ id, film thickness $0.25 \mu \mathrm{m}$; Thermo Scientific, San Jose, CA) was employed. The operating conditions were as follows: initial oven temperature, $60^{\circ} \mathrm{C}$ held for $2 \mathrm{~min}$, then gradually increased to $250^{\circ} \mathrm{C}$ at $4^{\circ} \mathrm{C} / \mathrm{min}$, and held for $20 \mathrm{~min}$; injector and detector temperatures, $250^{\circ} \mathrm{C}$; carrier gas, $1.0 \mathrm{~mL} / \mathrm{min}$ helium; injection volume, $1 \mu \mathrm{L}$; split ratio, $10: 1$. Quantitative data were compared with authentic active constituents including 1,8-cineole, alphaterpineol, linalool, and methyl eugenol, which were purchased from Sigma-Aldrich (St. Louis, MO).

2.2. Preparation of TSP and Placebo. Teabags (each containing $1.25 \mathrm{~g}$ of TSP powder) were manufactured at the Traditional Thai Medicine Hospital, Prince of Songkla University, Hat Yai Thailand, specifically for the present study. TSP teas were brewed by the addition of one teabag per $100 \mathrm{~mL}$ of freshly boiled water at $95^{\circ} \mathrm{C}$ for 1,3 , and $5 \mathrm{~min}$ without stirring. Each teabag was squeezed with a spoon and removed from the water before analysis. The antioxidant capacities of the teabags at a concentration of $1 \% \mathrm{v} / \mathrm{v}$ were determined as mentioned above. Sensory responses for colour, odour, taste, and overall acceptability were evaluated by 30 trained panellists using a 9-point hedonic scale (1 dislike very much; 5 neither like nor dislike; 9 like very much) [20]. The free radical scavenging activities were determined according to the elimination of DPPH and ABTS radicals [19].

The packaging of TSP tea and placebo (cornstarch) were identical, and they were sealed in opaque sterilized bags and placed inside a cardboard box. All boxes were identified by the letter "A" for placebo or "B" for TSP. To ensure the consistency of tea preparation, standard $100 \mathrm{~mL}$ ceramic cups with lids and specific written instructions for infusing the teabag with boiling water (without sugar or other sweetening agents) in the cup for $3 \mathrm{~min}$ before removing the teabag were included in the cardboard box. The identification of the box was known only by a licensed Thai traditional pharmacist who was not involved in data collection or analyses. The participants, investigators, and data gatherers were masked from the intervention procedures.

2.3. Study Design. This study was conducted from July 2013 to March 2014 at the Traditional Thai Medical Hospital, Prince of Songkla University in Hat Yai, Thailand. Considering $\alpha=0.05$, power of the test $=80 \%$, and achieving a $13 \mathrm{mg} / \mathrm{dL}$ difference in total cholesterol between the groups, the sample size was estimated to be 29 . Assuming $20 \%$ attrition, 35 participants in each group were included. The inclusion criteria for this study were as follows: (1) men or women between 20 and 55 years, (2) body mass index (BMI) of $23-29.9 \mathrm{~kg} / \mathrm{m}^{2}$ [21], (3) being in good health (patients with no medical histories of severe health problems such as hypertension, cardiovascular disease, dyslipidemia, clinical depression, diabetes mellitus, and thyroid diseases and no symptoms and abnormal findings during both physical examination and routine laboratory tests), and (4) willingness to fill out the questionnaires for this trial. Participants with the following conditions were excluded: (1) taking medication or supplements that might have an effect on metabolism or appetite and/or use of weight control therapy or antioxidant products within the last 3 months, (2) having a history of allergic reactions to medications or food, (3) being medically controlled or diagnosed with severe health problems such as hypertension, cardiovascular disease, dyslipidemia, clinical depression, diabetes mellitus, and thyroid diseases, and (4) being currently pregnant or lactating or both.

Letters were sent to 250 local participants who live near (less than $5 \mathrm{~km}$ ) the university to explain the purpose of the study and invite them to participate. A detailed explanation of the study design was given to the volunteers who expressed willingness to participate in the study. Written informed consent was obtained from the participants at the initiation of the study. All participants were free to withdraw at any time during the course of the study. The protocol was approved by the Medical Ethics Committee of Faculty of Traditional Thai Medicine, Prince of Songkla University (approval number: EC.56/B 06-001).

2.4. Interventions. All participants were randomly assigned to either the experimental (TSP) or control group (placebo) throughout this period. A random number between A0.01 and A0.70 was generated by the computer for each participant. The participants with a random number between A0.01 and A0.35 were assigned to the TSP group, while those with a random number between A0.36 and A0.70 were assigned to the placebo group. The eligible participants were assigned to receive either TSP tea or placebo twice daily, 20 min before breakfast and dinner, for 8 consecutive weeks. They received detailed advice on diet, exercise, and lifestyle modification as indicated in the 2013 AHA/ACC/TOS Guideline for the Management of Overweight and Obesity in Adults [22]. Patient compliance with the allocated treatments was monitored by filling a daily compliance chart. In addition, the compliance was measured by counting the product usage at weeks 4 and 8.

2.5. Measurements. All measurements were done after fasting for $12 \mathrm{~h}$ and determined at the baseline, 4 weeks, and endpoint (8th week) of the study for both groups. For the assessment of herbal drug efficacy or any side effects due to the treatment, insulin levels were measured by an electrochemiluminescence immunoassay (ECLIA-Roche Diagnostics GmbH, D-68298 Mannheim). The levels of FBG, cholesterol, low-density lipoprotein (LDL), high-density lipoprotein (HDL), triglyceride, albumin, total bilirubin, direct bilirubin, aspartate aminotransferase (AST), alanine aminotransferase (ALT), alkaline phosphatase (ALP), and gammaglutamyl transpeptidase (GGT) were determined with standard enzymatic colorimetric techniques and measured using the Hitachi 902 automatic analyser (Hitachi, Japan). In addition, all participants were given diaries to note the incidence and severity of symptoms and requested to report any adverse effects. 
TABLE 1: Antioxidant capacities and consumer acceptability of Tri-Sura-Phon teas with different brewing times.

Brewing time (min)

1

5

Antioxidant capacities* $(\% \pm \mathrm{SD})$

(i) DPPH radical scavenging capacity

(ii) ABTS radical scavenging capacity

Sensory analysis

(i) Colour

$85.69 \pm 1.70^{\mathrm{a}}$

$84.52 \pm 4.10^{\mathrm{a}}$

$89.45 \pm 0.63^{\mathrm{b}}$
$99.57 \pm 0.00^{\mathrm{b}}$

$88.49 \pm 0.24^{\mathrm{b}}$

(ii) Aroma

$6.60 \pm 1.77^{\mathrm{a}}$

$5.33 \pm 2.17^{\mathrm{a}}$

(iii) Taste

(iv) Overall acceptability
$4.73 \pm 2.02^{\mathrm{a}}$

$4.77 \pm 2.13^{\mathrm{a}}$
$6.63 \pm 1.77^{\mathrm{a}}$

$5.53 \pm 2.11^{\mathrm{a}}$

$5.23 \pm 2.19^{\mathrm{a}}$

$5.30 \pm 2.04^{\mathrm{a}}$
$100.00 \pm 0.00^{\mathrm{b}}$

$6.43 \pm 1.87^{\mathrm{a}}$

$5.23 \pm 2.11^{\mathrm{a}}$

$5.30 \pm 2.89^{\mathrm{a}}$

$5.30 \pm 1.97^{\mathrm{a}}$

${ }^{*}$ The tested teas exhibited DPPH and ABTS radical scavenging activities at concentration of $1 \%(\mathrm{v} / \mathrm{v})$.

${ }^{a, b}$ Means bearing different superscript letters in the same row are significantly different $(p<0.05)$.

2.6. Statistical Analysis. Data were analysed using the Statistical Package for the Social Sciences software (SPSS 19) for Windows. The antioxidant activities were tested in triplicate in at least three different experiments, and their results were presented as mean $\pm \mathrm{SD}$. The differences in laboratory parameters between the tested condition at baseline and after 4th and 8th week were assessed using a two-way ANOVA with Fisher's Least Significant Difference (LSD) as the post hoc test. A difference was considered statistically significant when the $p$ value was less than 0.05 .

\section{Results}

3.1. Characteristics of TSP. The optimal brewing times for TSP tea were determined with respect to the highest antioxidant activities observed with acceptable sensory parameters. According to the results (Table 1), no significant differences in sensory scores for infusion colour, aroma, test, and overall acceptability were found among TSP teas brewed for 1,3 , and $5 \mathrm{~min}$ at $95^{\circ} \mathrm{C}(p<0.05)$. Antioxidant capacity assessment of TSP tea showed that all samples were able to quench ABTS and DPPH radicals. TSP tea brewed for 3 and $5 \mathrm{~min}$ yielded significantly higher free radical scavenging activities than TSP tea infused for $1 \mathrm{~min}$. Brewing of TSP tea for $3 \mathrm{~min}$ at $95^{\circ} \mathrm{C}$ was chosen for further study because of its remarkable free radical scavenging capacity and slightly high sensory scores for infusion colour and aroma.

The yield of pale yellow oils obtained from TSP was $0.52 \%$ $(\mathrm{v} / \mathrm{w})$. The constituents of TSP oil include 1,8 -cineole $(27.7 \pm$ $0.3 \mathrm{mg} / \mathrm{mL})$, alpha-terpineol $(39.7 \pm 0.4 \mathrm{mg} / \mathrm{mL})$, linalool $(1.3 \pm 0.1 \mathrm{mg} / \mathrm{mL})$, and methyl eugenol $(7.7 \pm 0.4 \mathrm{mg} / \mathrm{mL})$. Brewed TSP tea used in this study possessed total phenolic content (expressed as gallic acid) equivalent to $3092.79 \pm$ $113.88 \mu \mathrm{g} / \mathrm{g}$ of dried extract and total flavonoid content (expressed as catechin) equivalent to $131.25 \pm 3.46 \mathrm{mg} / \mathrm{g}$ of dried extract.

3.2. Health Benefits of TSP Consumption on Overweight Volunteers. Of the 80 participants enrolled in this study, 61 completed the trial, and the following cases were excluded from the intervention: three volunteers refused to participate, seven did not attend the first-week visit, one showed abnormal liver function in tests, and eight were lost to follow-ups.
The CONSORT flowchart of the progress of the participants throughout the study is shown in Figure 2. There were no significant differences in baseline parameters between the two groups (Table $2 ; p \geq 0.05$ ).

The average triglyceride level in the TSP group decreased significantly from $147.6 \mathrm{mg} / \mathrm{dL}$ to 125.6 (at the 4 th week; $p=0.000$ ) and $96.1 \mathrm{mg} / \mathrm{dL}$ (at the 8th week; $p=0.001$ ) compared with that at the baseline (Table 2). In the TSP group, significant decreases in the average fasting levels of total cholesterol and LDL were additionally observed after 8 weeks of TSP treatment compared with that at the baseline ( $p=0.013$ for total cholesterol and $p=0.017$ for LDL). The average HDL level in the TSP group at the beginning of the study was $65.2 \mathrm{mg} / \mathrm{dL}$, and it increased significantly ( $p=0.005)$ to $72.4 \mathrm{mg} / \mathrm{dL}$ after 8 weeks of TSP treatment. No significant differences were observed in the placebo group before and after the intake in terms of total cholesterol, LDL, and HDL levels, but the average triglyceride levels in the placebo group decreased significantly $(p=0.002$ at the 4 th week). Moreover, changes of the cholesterol, LDL, and HDL levels following 8-week consumption of TSP were significantly higher than those following placebo treatment $(p=0.005$; Table 3$)$. No significant differences were found in terms of BMI and insulin levels; however, the FBG levels increased significantly in both TSP and placebo groups when compared between the baseline and endpoint.

No adverse effects were reported during the study. Neither the consumption of TSP infusion nor the placebo caused significant changes in the levels of direct bilirubin, AST, ALP, and GGT (Table 2). The TSP infusion lowered the blood levels of albumin (at the 8th week; $p=0.000$ ) and ALP (at the 8th week; $p=0.000$ ) significantly. In the placebo group, albumin level ( $p=0.008$ at the 4 th week) decreased compared to that at the baseline, whereas total bilirubin and albumin levels decreased when compared to the levels between the 4 th and 8th week ( $p=0.031$ for total bilirubin and $p=0.000$ for albumin).

\section{Discussion}

Traditionally, Thai herbal medicines are applied as a formulated decoction, which includes a specific combination of 


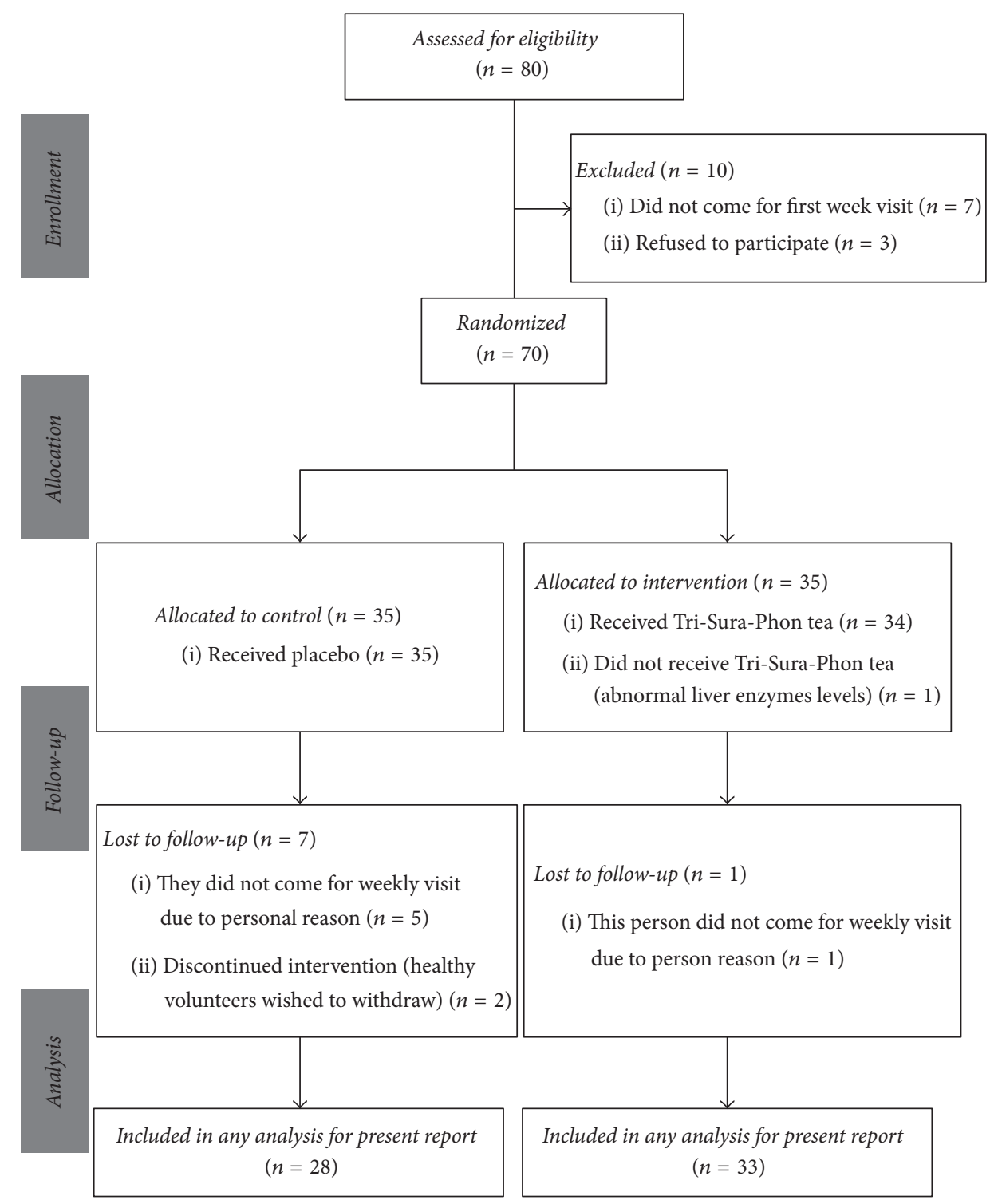

FIGURE 2: CONSORT diagram reflecting flow of study participants through the study.

different medicinal plants. These polyherbal medicines have been clinically used for thousands of years and currently play an indispensable role in the prevention and treatment of diseases. Based on the fact that the traditional Thai formulation was used as a rejuvenator and recorded in the Thai Pharmaceutical Textbook, the beneficial effects of TSP were determined in healthy overweight volunteers owing to its safety and efficacy.

The present results showed that an 8-week period of TSP tea drinking ( 2 cups per day) safely improves serum lipid profiles in overweight or obese volunteers. The consumption of this polyherbal tea, which contains antioxidant chemicals, was accountable for the decrease in highly atherogenic LDL$\mathrm{C}$ levels and increase in HDL-C levels. LDL-C particles are more easily oxidized, are less readily cleared, and have been linked to an increased risk of atherosclerosis, whereas
HDL-C particles provide protection against the formation of atherosclerotic plaques [23]. Therefore, evidence from our study is positively relevant to the control of dyslipidemia, which has been frequently observed in patients who are obese or have diabetes mellitus. No significant changes were found in the BMI of overweight volunteers following TSP tea consumption, which was in agreement with a 12 -week period of green tea extract consumption in obese women [24]. However, obese women who were treated with green tea extract that contains highly antioxidant polyphenols showed significant reductions in total cholesterol, triglyceride, and LDL-C levels and a marked increase in HDL-C levels [7, 24].

An increasing number of studies confirm that increased systemic oxidative stress in overweight or obese patients directly impacts the insulin sensitivity of metabolic organs, promotes inflammation, alters lipid metabolism, and causes 
TABLE 2: Effect of Tri-Sura-Phon tea drinking on body mass index, serum lipid profile, glucose and insulin levels, and liver function of healthy overweight volunteers.

\begin{tabular}{|c|c|c|c|c|}
\hline \multirow{2}{*}{ Parameters ${ }^{*}$} & \multirow{2}{*}{ Tested group } & \multicolumn{3}{|c|}{ Mean (SD) } \\
\hline & & Baseline & 4th week & 8th week \\
\hline \multirow{2}{*}{$\mathrm{BMI}\left(\mathrm{kg} / \mathrm{m}^{2}\right)$} & Tri-Sura-Phon & $27.7(4.5)$ & $27.6(4.5)$ & $27.6(4.5)$ \\
\hline & Placebo & $28.3(4.0)$ & $28.0(4.2)$ & $28.2(4.1)$ \\
\hline \multirow{2}{*}{ Total cholesterol (mg/dL) } & Tri-Sura-Phon & $223.7(37.6)$ & $213.5(29.2)$ & $201.3(36.2)^{\mathrm{B}}$ \\
\hline & Placebo & $210.5(33.0)$ & $213.6(37.2)$ & $211.9(42.6)$ \\
\hline \multirow{2}{*}{ Triglycerides (mg/dL) } & Tri-Sura-Phon & $147.5(74.3)^{3}$ & $79.3(24.2)^{\mathrm{A}, 1,2}$ & $103.4(40.2)^{\mathrm{B}, 1}$ \\
\hline & Placebo & $142.4(75.9)$ & $125.6(61.5)$ & $96.1(37.5)^{\mathrm{B}, \mathrm{C}}$ \\
\hline \multirow{2}{*}{ Low density lipoprotein (mg/dL) } & Tri-Sura-Phon & $130.5(40.5)$ & $129.7(30.6)$ & $108.5(37.6)^{\mathrm{B}, \mathrm{C}, 3}$ \\
\hline & Placebo & $116.2(35.5)$ & $125.0(33.7)$ & $131.7(44.0)$ \\
\hline \multirow{2}{*}{ High density lipoprotein (mg/dL) } & Tri-Sura-Phon & $63.4(12.8)$ & $68.0(14.1)^{3}$ & $72.4(13.4)^{\mathrm{B}, 1,3}$ \\
\hline & Placebo & $65.8(10.0)$ & $67.6(11.4)$ & $60.9(13.6)^{\mathrm{C}}$ \\
\hline \multirow{2}{*}{ FBG (mg/dL) } & Tri-Sura-Phon & $76.2(6.1)^{1,2,3}$ & $84.1(7.9)^{\mathrm{A}, 2,3}$ & $84.3(8.4)^{\mathrm{B}, 2,3}$ \\
\hline & Placebo & $81.5(12.0)$ & $91.4(12.8)^{\mathrm{A}}$ & $91.2(9.0)^{\mathrm{B}}$ \\
\hline \multirow{2}{*}{ Insulin level (uU/mL) } & Tri-Sura-Phon & $8.9(4.1)$ & $8.3(3.5)^{3}$ & $9.9(5.0)$ \\
\hline & Placebo & $10.9(7.0)$ & $8.7(4.2)$ & $10.9(7.0)$ \\
\hline \multirow{2}{*}{ Albumin (gm/dL) } & Tri-Sura-Phon & $4.6(0.5)^{2}$ & $4.5(0.5)^{2}$ & $4.1(0.5)^{\mathrm{B}, \mathrm{C}, 1,3}$ \\
\hline & Placebo & $4.5(0.5)$ & $4.1(0.4)^{\mathrm{A}}$ & $4.6(0.5)^{\mathrm{C}}$ \\
\hline \multirow{2}{*}{ Total bilirubin (mg/dL) } & Tri-Sura-Phon & $0.7(0.4)$ & $0.9(0.3)^{3}$ & $0.8(0.4)$ \\
\hline & Placebo & $0.8(0.5)$ & $0.9(0.4)$ & $0.6(0.5)^{\mathrm{C}}$ \\
\hline \multirow{2}{*}{ Direct bilirubin (mg/dL) } & Tri-Sura-Phon & $0.0(0.0)$ & $0.0(0.0)$ & $0.0(0.0)$ \\
\hline & Placebo & $0.0(0.2)$ & $0.0(0.0)$ & $0.0(0.0)$ \\
\hline \multirow{2}{*}{ AST (U/L) } & Tri-Sura-Phon & $20.1(5.6)^{2,3}$ & $22.6(6.8)$ & $19.8(4.3)^{2,3}$ \\
\hline & Placebo & $22.7(7.1)$ & $24.2(5.1)$ & $24.3(13.2)$ \\
\hline \multirow{2}{*}{$\operatorname{ALT}(\mathrm{U} / \mathrm{L})$} & Tri-Sura-Phon & $21.1(14.0)^{3}$ & $20.8(13.4)^{3}$ & $18.7(13.5)^{3}$ \\
\hline & Placebo & $22.5(11.6)$ & 20.7 (11.1) & $30.5(26.5)^{\mathrm{C}}$ \\
\hline \multirow{2}{*}{$\operatorname{ALP}(\mathrm{U} / \mathrm{L})$} & Tri-Sura-Phon & $78.1(20.1)$ & $76.0(19.5)$ & $69.6(21.3)$ \\
\hline & Placebo & $77.5(15.7)$ & $74.8(18.3)$ & $74.5(17.0)$ \\
\hline \multirow{2}{*}{ GGT (U/L) } & Tri-Sura-Phon & $25.0(15.7)$ & $25.7(16.0)$ & $25.1(17.7)$ \\
\hline & Placebo & $25.5(8.6)$ & $23.0(8.3)$ & $26.0(12.2)$ \\
\hline
\end{tabular}

Uppercase superscript letters indicate the significant differences in parameters between the baseline and week 4 (A) or the baseline and week 8 (B) or weeks 4 and $8(\mathrm{C})$ within the treatment.

Superscript numbers indicate the significant differences between the parameters at baseline (1), week 4 (2), or week 8 (3) among the treatments.

${ }^{*} \mathrm{BMI}=$ body mass index, $\mathrm{FBG}=$ fasting blood glucose, $\mathrm{AST}=$ aspartate aminotransferase, $\mathrm{ALT}=$ alanine aminotransferase, $\mathrm{ALP}=$ alkaline phosphatase, and GGT = gamma-glutamyl transpeptidase.

endothelial dysfunction [4]. Consuming antioxidative agents such as vitamin $\mathrm{C}$, vitamin $\mathrm{E}$, and selenium can reduce oxidative stress, and improve liver functions in obese patients [25], and reverse endothelial dysfunction in patients with coronary risk factors [26]. Therefore, lowering oxidative stress to prevent obesity-associated disorders establishes an interesting goal. The antioxidant mechanisms of medicinal plants may be controlled by stimulating endogenous antioxidant defence systems, scavenging reactive species, or chelating transition metals, thus stopping the progressive autooxidative damage [27]. In our current study, TSP showed effective antioxidant activity in part as a free radical scavenger, which could be especially beneficial for obesity-associated lowgrade inflammation.

TSP infusion is rich in flavonoids and polyphenols, which seem to be the key factors responsible for the antioxidant activities of TSP and demonstrate beneficial effects on serum lipid profiles. For example, polyphenols in green tea extract affect the absorption of cholesterol and glucose in the small intestine $[28,29]$. Phytosterols, curcumin, and (-)-epigallocatechin gallate have been found to affect lipid metabolism by reducing the absorption of cholesterol as well as gluconeogenesis and lipogenesis via activation of AMPactivated protein kinase or peroxisome proliferator-activated receptors [30]. Among the herbal components tested, notable antioxidant activity and phytochemical constituents were observed for C. bejolghota. This plant is widely used in Thai cuisine to add an aromatic flavour. Although the major active components of $C$. bejolghota had never been previously studied, preliminary phytochemical tests showed that methanol and water extracts prepared from C. bejolghota bark contained glycosides, saponins, tannins, and phenolic compounds [17]. In a similar study, Settharaksa et al. (2012) reported that $C$. bejolghota possesses the highest total phenolic content and ferric reducing antioxidant power among the tested ingredients in Kua-Khling curry paste, which is used in 
TABLE 3: Changes in clinical laboratory parameters after the consumption of Tri-Sura-Phon tea.

\begin{tabular}{|c|c|c|c|c|}
\hline \multirow{2}{*}{ Parameters $^{* *}$} & \multirow{2}{*}{ Tested groups } & \multicolumn{3}{|c|}{ Changes of evaluated values (SD) ${ }^{*}$} \\
\hline & & wk. 0 versus wk. 4 th & wk. 0 versus wk. 8th & wk. 4th versus wk. 8th \\
\hline \multirow{2}{*}{ BMI $\left(\mathrm{kg} / \mathrm{m}^{2}\right)$} & Tri-Sura-Phon & $0.1(0.4)^{3}$ & $0.1(0.5)^{3}$ & $0.0(0.3)^{1}$ \\
\hline & Placebo & $0.3(0.5)$ & $0.1(0.7)$ & $-0.2(0.5)^{\mathrm{A}, \mathrm{B}}$ \\
\hline \multirow{2}{*}{ Total cholesterol (mg/dL) } & Tri-Sura-Phon & $10.1(34.0)$ & $22.4(42.4)^{1,2,3}$ & $12.2(22.3)$ \\
\hline & Placebo & $-3.2(33.2)$ & $-1.5(29.8)$ & $1.7(29.6)$ \\
\hline \multirow{2}{*}{ Triglycerides (mg/dL) } & Tri-Sura-Phon & $68.2(79.3)^{1,3}$ & $44.1(80.8)$ & $-24.1(47.3)^{\mathrm{A}, \mathrm{B}, 1,2,3}$ \\
\hline & Placebo & $16.8(97.7)$ & $46.3(76.5)$ & $29.5(57.7)$ \\
\hline \multirow{2}{*}{ Low density lipoprotein (mg/dL) } & Tri-Sura-Phon & $0.9(38.8)$ & $22.1(49.2)^{A, 1,2,3}$ & $21.18(26.7)^{\mathrm{A}, 1,2,3}$ \\
\hline & Placebo & $-8.9(36.0)$ & $-15.5(38.9)$ & $-6.7(35.2)$ \\
\hline \multirow{2}{*}{ High density lipoprotein $(\mathrm{mg} / \mathrm{dL})$} & Tri-Sura-Phon & $-4.6(13.3)^{2,3}$ & $-9.0(15.3)^{1,2,3}$ & $-4.4(11.8)^{2,3}$ \\
\hline & Placebo & $-1.8(12.6)$ & $4.9(12.7)$ & $6.7(14.9)^{\mathrm{A}}$ \\
\hline \multirow{2}{*}{ FBG (mg/dL) } & Tri-Sura-Phon & $-7.8(7.8)^{3}$ & $8.1(7.0)^{3}$ & $-0.3(7.2)^{\mathrm{A}, \mathrm{B}, 1,2}$ \\
\hline & Placebo & $-10.0(7.7)$ & $-9.7(8.1)$ & $0.2(8.3)^{\mathrm{A}, \mathrm{B}}$ \\
\hline \multirow{2}{*}{ Insulin level $(\mathrm{uU} / \mathrm{mL})$} & Tri-Sura-Phon & $0.5(4.0)$ & $-1.0(4.6)$ & $-1.7(4.4)$ \\
\hline & Placebo & $-0.2(5.9)$ & $-2.4(8.2)$ & $-2.0(7.7)$ \\
\hline \multirow{2}{*}{ Albumin (gm/dL) } & Tri-Sura-Phon & $0.1(0.4)^{3}$ & $0.4(0.7)^{\mathrm{A}, 2,3}$ & $0.1(0.5)^{\mathrm{B}, 2}$ \\
\hline & Placebo & $0.2(0.5)$ & $0.0(0.2)$ & $-0.3(0.5)^{\mathrm{A}}$ \\
\hline \multirow{2}{*}{ Total bilirubin (mg/dL) } & Tri-Sura-Phon & $0.0(0.2)$ & $0.0(0.0)^{2,3}$ & $0.1(0.3)$ \\
\hline & Placebo & $0.0(0.2)$ & $0.1(0.3)^{\mathrm{A}}$ & $0.1(0.4)^{\mathrm{A}}$ \\
\hline \multirow{2}{*}{ Direct bilirubin $(\mathrm{mg} / \mathrm{dL})$} & Tri-Sura-Phon & $0.0(0.0)$ & $0.0(0.0)$ & $0.0(0.0)$ \\
\hline & Placebo & $0.0(0.2)$ & $0.0(0.2)$ & $0.0(0.0)$ \\
\hline \multirow{2}{*}{$\operatorname{AST}(\mathrm{U} / \mathrm{L})$} & Tri-Sura-Phon & $-2.5(7.2)$ & $0.2(5.3)$ & $2.8(5.2)^{\mathrm{A}, 1,2}$ \\
\hline & Placebo & $-1.5(7.4)$ & $-1.6(9.8)$ & $-0.1(13.4)$ \\
\hline \multirow{2}{*}{$\operatorname{ALT}(\mathrm{U} / \mathrm{L})$} & Tri-Sura-Phon & $0.3(10.2)^{2,3}$ & $2.3(11.4)^{2,3}$ & $2.0(7.7)^{2,3}$ \\
\hline & Placebo & $1.8(8.9)$ & $-7.9(24.1)^{\mathrm{A}}$ & $-9.7(23.9)^{\mathrm{A}}$ \\
\hline \multirow{2}{*}{$\operatorname{ALP}(\mathrm{U} / \mathrm{L})$} & Tri-Sura-Phon & $2.1(9.3)$ & $8.6(12.4)^{\mathrm{A}, 3}$ & $6.4(11.2)$ \\
\hline & Placebo & $2.7(15.1)$ & $3.0(11.4)$ & $0.36(16.8)$ \\
\hline \multirow{2}{*}{ GGT (U/L) } & Tri-Sura-Phon & $-0.7(9.4)$ & $-0.1(8.7)$ & $0.6(4.1)$ \\
\hline & Placebo & $2.5(5.1)$ & $-0.5(8.5)$ & $-3.0(9.6)^{\mathrm{A}}$ \\
\hline
\end{tabular}

Uppercase superscript letters indicate significant differences in changes of parameters between baseline and week 4 (A) or baseline and week 8 (B) or weeks 4 and $8(C)$ in the same treatment.

Superscript numbers indicate significant differences in changes of parameters between baseline and week 4 (1) or baseline and week 8 (2) or weeks 4 and 8 (3) among the treatments.

${ }^{*}$ Negative values correspond to increases from baseline and positive values correspond to decreases from baseline.

** $\mathrm{BMI}=$ body mass index, $\mathrm{FBG}=$ fasting blood glucose, $\mathrm{AST}=$ aspartate aminotransferase, $\mathrm{ALT}=$ alanine aminotransferase, $\mathrm{ALP}=$ alkaline $\mathrm{phosphatase}$, and GGT = gamma-glutamyl transpeptidase.

Thai cuisine [31]. It should be further noted that the methanol extract of C. bejolghota bark significantly reduced cholesterol, triglyceride, and LDL-C levels and decreased HDL-C levels in streptozotocin- (STZ-) induced diabetic rats [17]. In addition, the extract has been found to reduce lipid peroxidation and improve the level of catalase and glutathione in their livers. However, there is no available report for the hypolipidemic and antioxidant effects of C. parthenoxylon. Jia et al. (2009) found that the water-soluble polyphenolic oligomers from C. parthenoxylon have hypoglycemic effects in both normal and STZ-induced diabetic rats [16]. Our results showed that the antioxidant activities and contents of total phenolics and flavonoids of A. crassna were less than those of the extracts of $C$. parthenoxylon and C. bejolghota. Essential oils extracted from A. crassna possess antioxidant and anticancer activities, but a recent study revealed that feeding these essential oils to mice did not affect the triglyceride, LDL-C, and HDL-C levels [18]. It should be noted that 1,8-cineole [32], linalool [33], and methyl eugenol [34], which are components of TSP essential oils, have been reported to positively affect the serum lipid profile in in vivo models. Based on these results, it may be hypothesized that the beneficial effects of TSP tea observed in healthy overweight volunteers may be primarily caused by $C$. parthenoxylon and C. bejolghota. However, studies investigating the active constituents and mechanisms that mediate lipophilic effects of Tri-Sura-Phon tea and the influence of tea consumption on human oxidative status need to be pursued.

The standardization of polyherbal formulation according to its active components, as well as the use of a placebo having no effect on serum lipid profile, can be cited as the strengths of the current study. The limitations of the study include 
small sample size with a narrow range of participant ages and BMI as well as the use of healthy subjects. Although, having a placebo arm is the strength of the present study, there are differences in the appearance of colour, odour, and taste between the placebo and TSP infusion should be noted as the limitation. Lack of qualitative information on the diet and exercise as well as quantitative data on energy and nutrient intake of the participants can be also mentioned as the limitation of this study.

\section{Conclusions}

In conclusion, our findings showed that the total cholesterol, triglyceride, LDL-C, and HDL-C levels in overweight volunteers were affected by taking Tri-Sura-Phon tea, which might be a useful adjunctive remedy for overweight patients. The observed health benefits may, at least in part, be associated with the free radical scavenging properties of the tea. Further trials on the long-term safety and efficacy of this tea in vivo and in the treatment of borderline hyperlipidemia are currently being investigated by our research group.

\section{Conflicts of Interest}

The authors have read and understood eCAM policy on declaration of interests and declare the following interest: Miss Wipawee Chanthasri was funded by Natural Product Research Center of Excellence Postgraduate Scholarship, Prince of Songkla University, Hat Yai, Songkhla 90110, Thailand.

\section{Acknowledgments}

This work was supported by Grants for a General Researcher, the Annual Income Budget of Prince of Songkla University [TTM580727S; 2014-2016], and partly supported by TRF Senior Research Scholar, the Thailand Research Fund [Grant no. RTA5880005].

\section{References}

[1] S. Wang, W. Ma, Z. Yuan et al., "Association between obesity indices and type 2 diabetes mellitus among middle-aged and elderly people in Jinan, China: a cross-sectional study," $B M J$ Open, vol. 6, no. 11, Article ID e012742, 2016.

[2] L. Liu, K. Ikeda, M. Chen et al., "Obesity, emerging risk in China: trend of increasing prevalence of obesity and its association with hypertension AND hypercholesterolaemia among the Chinese," Clinical and Experimental Pharmacology and Physiology, vol. 31, no. 2, pp. S8-S10, 2004.

[3] A. K. Palmer and J. L. Kirkland, "Aging and adipose tissue: potential interventions for diabetes and regenerative medicine," Experimental Gerontology, vol. 86, pp. 97-105, 2016.

[4] S. Furukawa, T. Fujita, M. Shimabukuro et al., "Increased oxidative stress in obesity and its impact on metabolic syndrome," The Journal of Clinical Investigation, vol. 114, no. 12, pp. 1752-1761, 2004.
[5] P. Bagri, M. Ali, V. Aeri, M. Bhowmik, and S. Sultana, "Antidiabetic effect of Punica granatum flowers: effect on hyperlipidemia, pancreatic cells lipid peroxidation and antioxidant enzymes in experimental diabetes," Food and Chemical Toxicology, vol. 47, no. 1, pp. 50-54, 2009.

[6] S. Kumari, M. Deori, R. Elancheran, J. Kotoky, and R. Devi, "In vitro and In vivo antioxidant, anti-hyperlipidemic properties and chemical characterization of Centella asiatica (L.) extract," Frontiers in Pharmacology, vol. 7, article 400, 2016.

[7] J. Suliburska, P. Bogdanski, M. Szulinska, M. Stepien, D. PupekMusialik, and A. Jablecka, "Effects of green tea supplementation on elements, total antioxidants, lipids, and glucose values in the serum of obese patients," Biological Trace Element Research, vol. 149, no. 3, pp. 315-322, 2012.

[8] S. Kianbakht and F. H. Dabaghian, "Improved glycemic control and lipid profile in hyperlipidemic type 2 diabetic patients consuming Salvia officinalis L. leaf extract: a randomized placebo. Controlled clinical trial," Complementary Therapies in Medicine, vol. 21, no. 5, pp. 441-446, 2013.

[9] P. Jandaghi, M. Noroozi, H. Ardalani, and M. Alipour, "Lemon balm: a promising herbal therapy for patients with borderline hyperlipidemia - a randomized double-blind placebocontrolled clinical trial," Complementary Therapies in Medicine, vol. 26, no. 6, pp. 136-140, 2016.

[10] H. Fallah Huseini, S. Hasani-Rnjbar, N. Nayebi et al., "Capparis spinosa L. (Caper) fruit extract in treatment of type 2 diabetic patients: a randomized double-blind placebo-controlled clinical trial," Complementary Therapies in Medicine, vol. 21, no. 5, pp. 447-452, 2013.

[11] M. S. Baliga, S. Meera, B. Mathai, M. P. Rai, V. Pawar, and P. L. Palatty, "Scientific validation of the ethnomedicinal properties of the Ayurvedic drug Triphala: a review," Chinese Journal of Integrative Medicine, vol. 18, no. 12, pp. 946-954, 2012.

[12] S. Saravanan, R. Srikumar, S. Manikandan, N. Jeya Parthasarathy, and R. Sheela Devi, "Hypolipidemic effect of triphala in experimentally induced hypercholesteremic rats," Yakugaku Zasshi, vol. 127, no. 2, pp. 385-388, 2007.

[13] A. Pradeep, D. K. Suke, S. S. Martande, S. P. Singh, K. Nagpal, and S. B. Naik, "Triphala, a new herbal mouthwash for the treatment of gingivitis: a randomized controlled clinical trial," Journal of Periodontology, vol. 87, no. 11, pp. 1352-1359, 2016.

[14] C. Picheansoonthon and V. Jerawong, Thai Pharmaceutical Textbook No. 5 Materia Medica (in Thai), Amarin Printing, Bangkok, Thailand, 2001.

[15] S. Chusri, P. Singthong, and T. Kaewmanee, "Antioxidant, anticancer, and cytotoxic effects of Thai traditional herbal preparations consumed as rejuvenators," CYTA-Journal of Food, vol. 13, no. 1, pp. 40-48, 2015.

[16] Q. Jia, X. Liu, X. Wu et al., "Hypoglycemic activity of a polyphenolic oligomer-rich extract of Cinnamomum parthenoxylon bark in normal and streptozotocin-induced diabetic rats," Phytomedicine, vol. 16, no. 8, pp. 744-750, 2009.

[17] B. Gogoi, B. B. Kakoti, S. Borah, and N. S. Borah, "Antihyperglycemic and in vivo antioxidative activity evaluation of Cinnamomum bejolghota (Buch.-Ham.) in streptozotocin induced diabetic rats: an ethnomedicinal plant in Assam," Asian Pacific Journal of Tropical Medicine, vol. 7, supplement 1, pp. S427-S434, 2014.

[18] S. S. Dahham, L. E. A. Hassan, M. B. K. Ahamed, A. S. Abdul Majid, A. M. S. Abdul Majid, and N. N. Zulkepli, "In vivo toxicity and antitumor activity of essential oils extract 
from agarwood (Aquilaria crassna)," BMC Complementary and Alternative Medicine, vol. 16, no. 7, article 236, 2016.

[19] G. Miliauskas, P. R. Venskutonis, and T. A. Van Beek, "Screening of radical scavenging activity of some medicinal and aromatic plant extracts," Food Chemistry, vol. 85, no. 2, pp. 231-237, 2004.

[20] T. Moodley, E. O. Amonsou, and S. Kumar, "Nutritional quality and acceptability of Buddleja saligna herbal tea," Journal of Food Science and Technology, vol. 52, no. 11, pp. 7519-7524, 2015.

[21] R. B. Thandassery, S. Appasani, T. D. Yadav et al., "Implementation of the Asia-Pacific guidelines of obesity classification on the APACHE-O scoring system and its role in the prediction of outcomes of acute pancreatitis: a study from India," Digestive Diseases and Sciences, vol. 59, no. 6, pp. 1316-1321, 2014.

[22] M. D. Jensen, D. H. Ryan, C. M. Apovian et al., "2013 AHA/ACC/TOS guideline for the management of overweight and obesity in adults: a report of the American college of cardiology/American heart association task force on practice guidelines and the obesity society," Journal of the American College of Cardiology, vol. 63, no. 25_PA, 2014.

[23] L. Badimon and G. Vilahur, "LDL-cholesterol versus HDLcholesterol in the atherosclerotic plaque: inflammatory resolution versus thrombotic chaos," Annals of the New York Academy of Sciences, vol. 1254, no. 1, pp. 18-32, 2012.

[24] C.-H. Hsu, T.-H. Tsai, Y.-H. Kao, K.-C. Hwang, T.-Y. Tseng, and P. Chou, "Effect of green tea extract on obese women: a randomized, double-blind, placebo-controlled clinical trial," Clinical Nutrition, vol. 27, no. 3, pp. 363-370, 2008.

[25] S. B. Murer, I. Aeberli, C. P. Braegger et al., "Antioxidant supplements reduced oxidative stress and stabilized liver function tests but did not reduce inflammation in a randomized controlled trial in obese children and adolescents," Journal of Nutrition, vol. 144, no. 2, pp. 193-201, 2014.

[26] T. Heitzer, T. Schlinzig, K. Krohn, T. Meinertz, and T. Münzel, "Endothelial dysfunction, oxidative stress, and risk of cardiovascular events in patients with coronary artery disease," Circulation, vol. 104, no. 22, pp. 2673-2678, 2001.

[27] J.-M. Lü, P. H. Lin, Q. Yao, and C. Chen, "Chemical and molecular mechanisms of antioxidants: experimental approaches and model systems," Journal of Cellular and Molecular Medicine, vol. 14, no. 4, pp. 840-860, 2010.

[28] K. Lochocka, J. Bajerska, A. Glapa et al., "Green tea extract decreases starch digestion and absorption from a test meal in humans: a randomized, placebo-controlled crossover study," Scientific Reports, vol. 5, Article ID 12015, 2015.

[29] S. I. Koo and S. K. Noh, "Green tea as inhibitor of the intestinal absorption of lipids: potential mechanism for its lipid-lowering effect," The Journal of Nutritional Biochemistry, vol. 18, no. 3, pp. 179-183, 2007.

[30] S. Feng, L. Reuss, and Y. Wang, "Potential of natural products in the inhibition of adipogenesis through regulation of PPAR $\gamma$ expression and/or its transcriptional activity," Molecules, vol. 21, no. 10, p. 1278, 2016.

[31] S. Settharaksa, A. Jongjareonrak, P. Hmadhlu, W. Chansuwan, and S. Siripongvutikorn, "Flavonoid, phenolic contents and antioxidant properties of thai hot curry paste extract and its ingredients as affected of $\mathrm{pH}$, solvent types and high temperature," International Food Research Journal, vol. 19, no. 4, pp. 1581-1587, 2012.

[32] K.-H. Cho, "1,8-Cineole protected human lipoproteins from modification by oxidation and glycation and exhibited serum lipid-lowering and anti-inflammatory activity in zebrafish," BMB Reports, vol. 45, no. 10, pp. 565-570, 2012.
[33] H.-J. Jun, J. H. Lee, J. Kim et al., "Linalool is a PPAR $\alpha$ ligand that reduces plasma TG levels and rewires the hepatic transcriptome and plasma metabolome," The Journal of Lipid Research, vol. 55, no. 6, pp. 1098-1110, 2014.

[34] K. Venkadeswaran, A. R. Muralidharan, T. Annadurai et al., "Antihypercholesterolemic and antioxidative potential of an extract of the plant, Piper betle, and its active constituent, eugenol, in triton WR-1339-Induced hypercholesterolemia in experimental rats," Evidence-Based Complementary and Alternative Medicine, vol. 2014, Article ID 478973, 11 pages, 2014. 


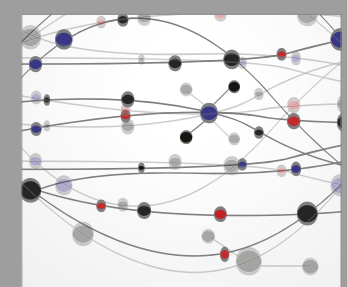

The Scientific World Journal
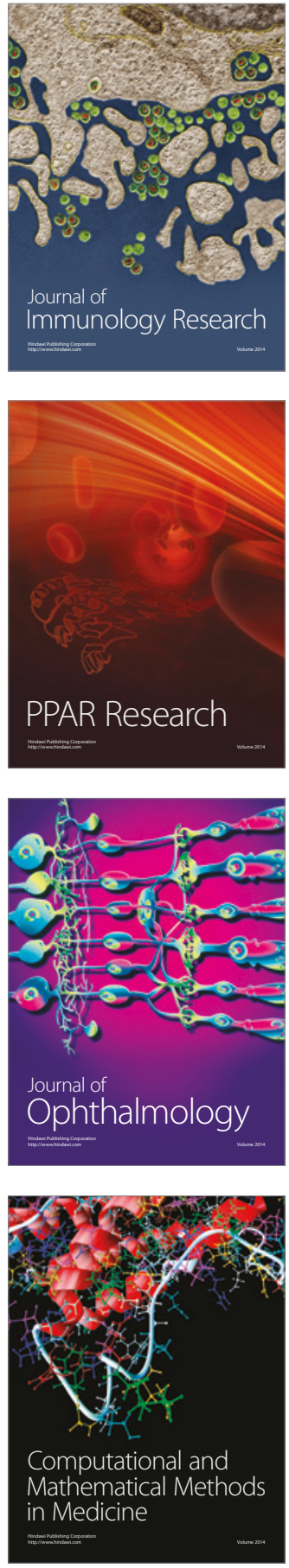

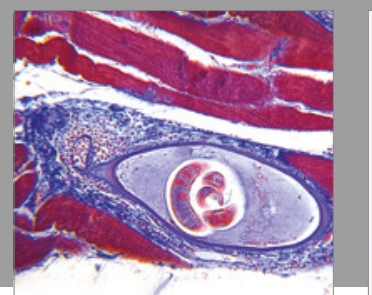

Gastroenterology Research and Practice
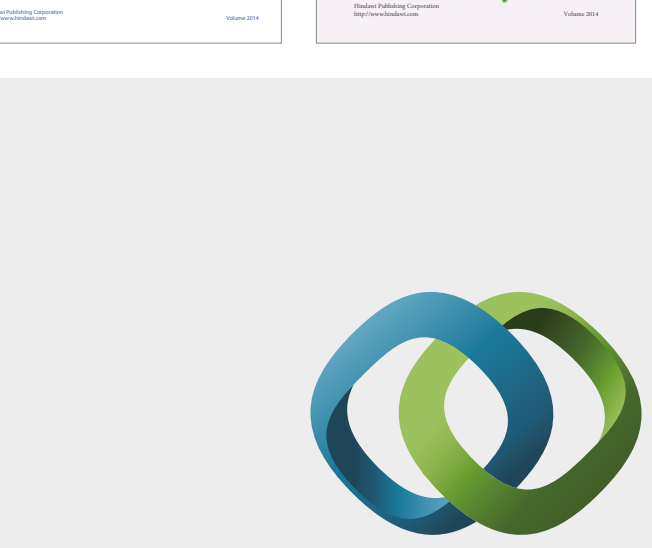

\section{Hindawi}

Submit your manuscripts at

https://www.hindawi.com
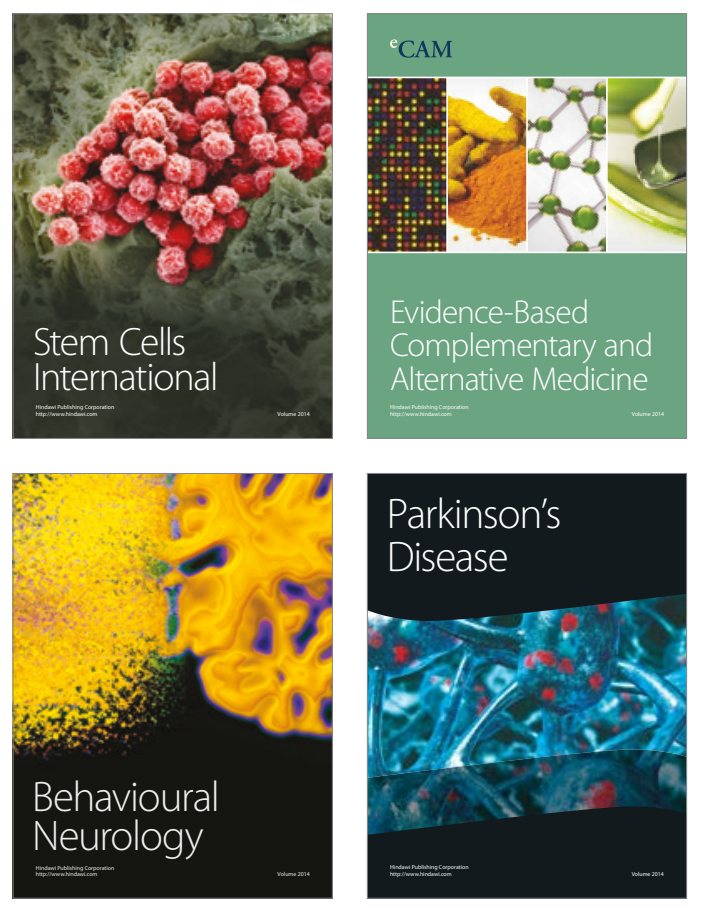
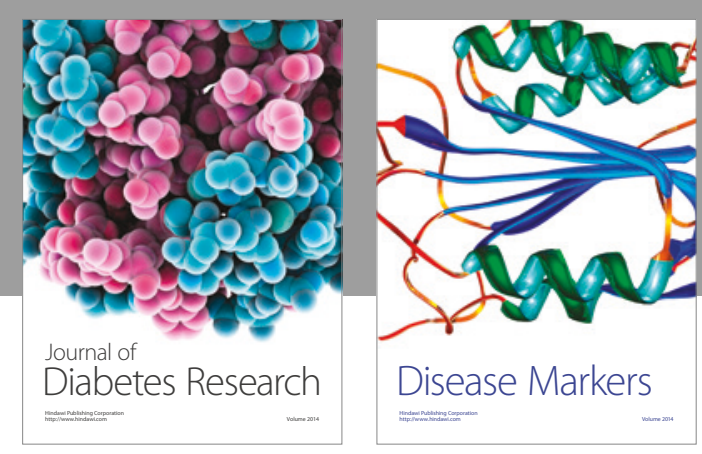

Disease Markers
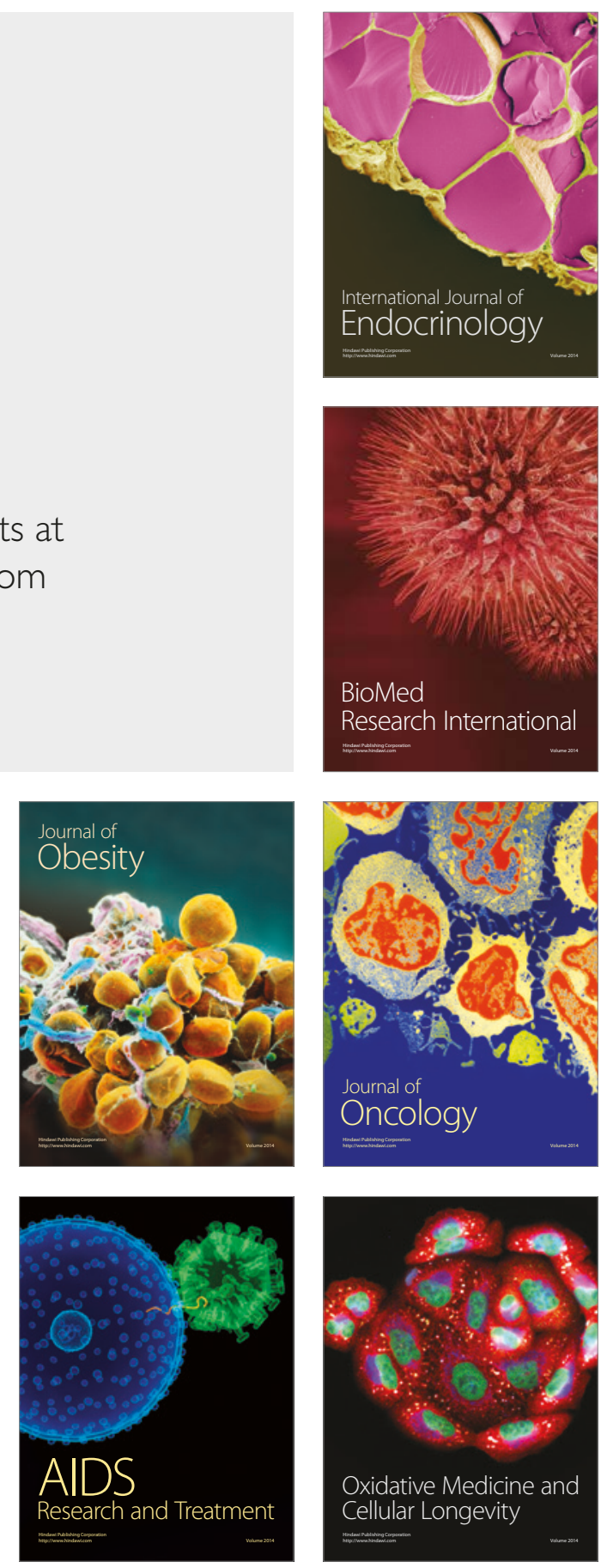